\title{
MALFORMACIONES CONGÉNITAS EN LA CRIANZA DE CERDOS DEL SECTOR NO ESPECIALIZADO EN EL ORIENTE DE CUBA
}

\author{
CONGENITAL MALFORMATIONS IN NON SPECIALIZED PIG BREEDING \\ SECTOR IN THE EASTERN CUBA
}

\author{
Reyes Ávila, I.R. ${ }^{1 *}$, Pérez Pineda, E. ${ }^{1}$, Pérez Freeman, F. ${ }^{1}$ y Reyes Ávila, L.E. ${ }^{2}$ \\ ${ }^{1}$ Universidad de Granma. Km 17 1⁄2. Peralejo. Bayamo. Granma. Cuba. *rene@udg.co.cu \\ ${ }^{2}$ Asovino Sociedad Cooperativa. Zamora. España.
}

PALABRAS CLAVE ADICIONALES

Cerdos Criollos.

\section{RESUMEN}

Para cuantificar la incidencia de malformaciones congénitas en cerdos del sector no especializado, en el oriente de Cuba, se observaron 325 camadas procedentes de diferentes genotipos de las razas más utilizadas en la zona. Se detectaron las malformaciones por observación, se cuantificaron y se determinó su significación con respecto al total de crías. La hernia inguinoescrotal resultó ser la más frecuente. Se concluye que el número de partos que presentan malformaciones es alto $(9,07 \%$ del total), y por tanto, sería necesario mayor rigor en la selección de reproductores en el sector no especializado.

\section{SUMMARY}

Whit the objective of quantify the incidence of pig congenital malformations in the non specialized sector in eastern of Cuba, an amount of 325 litters, from different genotypes of the most frequently used breeds in this zone was analyzed. The malformations were detected by observation and quantified, its significance was determined with respect to the total amount of piglets. Inguinoescrotal hernia resulted to be the most frequent of all. It was concluded that the number of births presenting malformations is very high, $9.07 \%$ of the total of cases. An alert is emitted for a necessity of being rigorous in selecting breeders from non specialized productive sector.

\section{INTRODUCCIÓN}

El cerdo Criollo de Cuba, patrimonio

Recibido: 13-3-08. Aceptado: 1-4-08.

\section{AdDitionAL KEYWORDS \\ Creole pig.}

genético importante, constituye en zonas rurales una fuente importante de carne y grasa a bajo costo gracias a sus cualidades como: alta resistencia a las enfermedades, incluyendo las parasitarias y consumo de alimentos no convencionales de los que obtienen en muchos casos todos los elementos nutritivos para vivir, desarrollarse y reproducirse. La adaptación a las condiciones más extremas de tenencia, le ha permitido mantener una población, aunque baja, si estable, a pesar de la continua introducción de razas y genotipos, sobre todo más productivos, pero más exigentes, desde el punto de vista del manejo, la alimentación y la vigilancia de la salud.

Se ha podido observar con relativa frecuencia la aparición de malformaciones congénitas, de ellas algunas sin solución y por tanto incompatibles con la vida. Otras, como las hernias en sus diferentes formas, las contracturas de los tendones flexores y en algunos casos atresia anal, son solubles por medio de la cirugía en etapas tempranas de la vida del tarado que puede garantizar su desarrollo y posterior consumo, aunque no su utilización como reproductor, ya que ello comprometería la salud hereditaria de las futuras camadas.

El objetivo del presente trabajo, fue cuantificar la incidencia de las malformaciones 


\section{REYES ÁVILA, PÉREZ PINEDA, PÉREZ FREEMANY REYES ÁVILA}

congénitas en cerdos del sector no especializado en el oriente de Cuba.

\section{MATERIAL Y MÉTODOS}

Durante más de 3 años, se registraron datos de 348 partos de cerdas preñadas por verracos de diferentes genotipos, pertenecientes a pequeños criadores individuales en la región oriental de Cuba, así como de cerditos afectados de algunas de las malformaciones congénitas, algunas compatibles con la vida y posibles de solucionar por métodos quirúrgicos que en este lapso de tiempo han sido estudiadas en la Universidad de Granma. Por la característica de los datos, se realizó un análisis estadístico elemental, basado fundamentalmente en cálculos porcentuales.

\section{RESULTADOSYDISCUSIÓN}

En la tabla I, se puede apreciar el total de partos afectados por patologías congénitas, el número y el porcentaje de animales afectados, observándose que en 31 de los 348 partos analizados (2648 cerditos nacidos vivos), se observó algún caso de malformación, lo que representa un 9,07\%, se observó en 14 machos hernia inguinoescrotal $(45,2 \%)$, en 4 hernia umbilical $(12,9 \%)$, en 4 atresia anal (12,9\%), también afectando sólo a animales machos, dos ca- sos de atresia anal con fístula rectovaginal $(6,5 \%)$, dos casos de contractura de los tendones flexores de las extremidades anteriores $(6,5 \%)$, dos casos de esquistosoma reflejo $(6,5 \%)$ y un caso de microcefalia $(3,2 \%)$.

Según Pascual del Cueto et al. (2000) y Homedes y Haro (1967) las hernias inguinal y escrotal en los animales machos se producen al permanecer abierto el canal inguinal, las asas intestinales o parte del epiplón atraviesan la apófisis vaginal de la fascia transversa y del peritoneo a través del anillo inguinal interior, llegando a una cámara secundaria de la cavidad herniaria. La herencia es autonómica, resesiva, subvital, limitada por el sexo o por motivos anatómicos se presenta sólo en un sexo.

Se han encontrado camadas en que la totalidad de los cerditos machos estaban afectados por este tipo de hernia (figura 1). Brito (2001) y Pascual del Cueto et al. (2000), describen la hernia umbilical como la hernia en el área umbilical, cubierta de piel y de causa poligénica.

Respecto a la atresia del ano, Pascual del Cueto et al. (2000), plantean que la ausencia del esfínter anal está generalmente asociada a un desarrollo incompleto del recto. Los animales machos mueren entre los tres o cuatro días de nacidos, mientras que en las hembras una perforación vaginal les permi-

Tabla I. Patologías congénitas observadas en 348 camadas. (Congenital pathologies observed).

\begin{tabular}{|c|c|c|c|c|c|}
\hline \multirow[t]{2}{*}{ Tipo de patología } & \multicolumn{2}{|c|}{ Sobre partos afectados } & \multicolumn{2}{|c|}{ Sobre afectados } & \multirow{2}{*}{$\begin{array}{c}\text { nacidos } \\
\% \text { o }\end{array}$} \\
\hline & cantidad & $\%$ & cantidad & $\%$ & \\
\hline Hernia inguinoescrotal & 14 & 45,2 & 51 & 70,8 & 19,3 \\
\hline Hernia umbilical & 4 & 12,9 & 7 & 9,7 & 2,6 \\
\hline Atresia anal & 4 & 12,9 & 4 & 5,6 & 1,5 \\
\hline Contractura del tendón flexor & 2 & 6,5 & 2 & 2,8 & 0,76 \\
\hline Atresia anal con fístula rectovaginal & 2 & 6,5 & 2 & 2,8 & 0,76 \\
\hline Esquistosoma reflejo & 2 & 6,5 & 2 & 2,8 & 0,76 \\
\hline Criptorquidia & 2 & 6,5 & 3 & 4,7 & 1,13 \\
\hline Microcefalia & 1 & 3,2 & 1 & 1,4 & 0,4 \\
\hline TOTAL & 31 & 100 & 72 & 100 & 1000 \\
\hline
\end{tabular}

Archivos de zootecnia vol. 59, núm. 228, p. 602. 


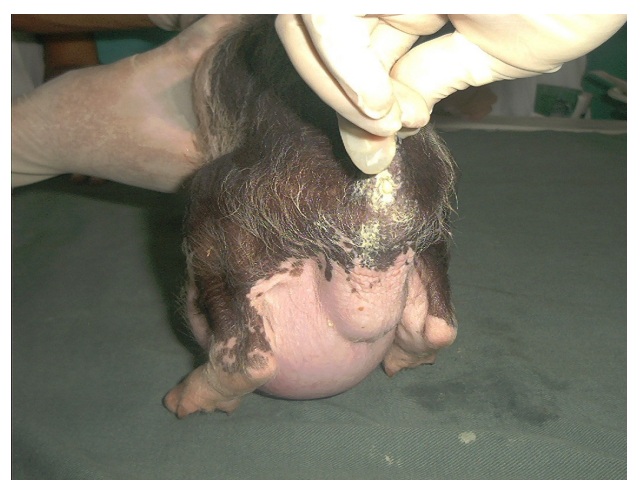

Figura 1. Hernia inguinoescrotal. (Inguinoescrotal hernia).

te evacuar a través de la vulva. La herencia es autosómica, recesiva, semiletal. De acuerdo con lo expuesto por Felipe (2004), esto puede ser debido a un fallo en el mecanismo de muerte celular, proceso llamado apoptosis, ocurre durante el desarrollo embrionario y es un mecanismo genéticamente programado, específicamente la luz del tubo intestinal de los embriones presenta áreas cerradas por la proliferación celular que se abren durante la gestación. Si la reapertura no ocurre se genera una atresia intestinal.

Los casos atendidos fueron sometidos a una operación sencilla, con la realización de una incisión en forma de cruz en el lugar que fisiológicamente ocuparía el ano, se formó en todos los casos una fístula que permitió evacuar las heces durante su vida sin otros contratiempos. Este propio modo de proceder es recomendado por Johansson y Rendel (1972).

Respecto a la fístula rectovaginal, Pascual del Cueto et al. (2000), plantean que el ano falta y el recto se comunica con la vagina por medio de una fístula. La herencia es autonómica, recesiva, letal. En estos casos el tratamiento quirúrgico resulta más complicado, ya que se hace necesario cerrar el trayecto fistuloso y abrir un orificio que sustituirá al ano.

La contractura del tendón flexor de las extremidades anteriores, es mencionada por

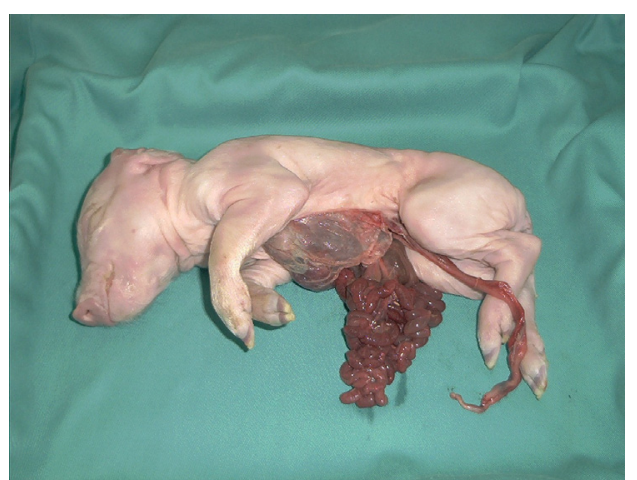

Figura 2. Esquistosoma reflejo incompleto. (Incomplete reflected schistosoma).

Frazer(1991) en el Manual Merk y por Quiles (2004), como una causa importante de mortalidad de crías porcinas. Con la aplicación fundamentalmente de vitaminas del complejo B y Vitamina A, así como alguna fisioterapia, en un plazo alrededor de 15 días, se logra que el animal adquiera la postura correcta y la posibilidad de caminar fisiológicamente.

Respecto al esquistosoma reflejo, el Diccionario terminológico de ciencias médicas (1984), plantea que se trata de un término de origen griego y no es más que un monstruo fetal con el abdomen hendido, por su parte Brito (2001) y Arthur (1966), exponen que ocurre en los rumiantes y en el cerdo, el principal defecto está en el esqueleto, con angulación aguda de la columna vertebral del feto, lo que causa aproximación dorsal de la cabeza a la cola. Las cavidades torácicas y abdominales están incompletas en la parte ventral, de manera que las vísceras quedan expuestas.

En los casos observados, se trata de esquistosomas incompletos (figura 2), pues sólo se presenta la falta de la pared abdominal y torácica, con la eventración de las vísceras, al no ser posible reparar el defecto congénito se produjo la muerte. Es realmente una malformación incompatible con la vida (Reyes et al., 2006).

Respecto a la microcefalia sólo se en- 


\section{REYES ÁVILA, PÉREZ PINEDA, PÉREZ FREEMANY REYES ÁVILA}

contraron criterios relacionados con la acefalia o acrania, sobre la que Pulgarón y Pascual del Cueto (1979) describen como la falta completa del cráneo, la cabeza aparece como cortada, se trata de una herencia autosómica, letal, dominante. Aquí se considera necesario citar también las fallas en la inducción referida por Felipe (2004), quien expone que muchos componentes embrionarios se desarrollan por la acción inductora de estructuras preexistentes, por lo que la ausencia o carencia de inducción, provoca que el nuevo órgano no se forme dando lugar a la agenesia. En el caso estudiado la cabeza era extremadamente pequeña, casi imposible de distinguir sus partes, con excepción de las orejas que se encontraban en su posición, aunque de tamaño muy pequeño.

Respecto a las razas, la mayor incidencia estuvo en el cruce Criolla por Yorkshire con 17 partos $(58,8 \%)$, en Criolla 9 partos $(31,0 \%)$, Criolla por Hampshire 2 partos $(6,9 \%)$ y Criolla por York-Land 1 parto $(3,5 \%)$.

\section{BIBLIOGRAFÍA}

Arthur, R.G. 1966. Anomalías en el desarrollo embrionario. En: Obstetricia Veterinaria de Wrigt. $3^{a}$ Edición. Ed. Interamericana S.A. México. pp. 84-110.

Brito, R. 2001. Anomalías Congénitas. En: Patología de la reproducción animal. Ed. Félix Varela. La Habana. pp. 124-131.

Diccionario terminológico de ciencias médicas. 1984. Ed. Científico Técnica. La Habana. 371 pp.

Felipe, A.E. 2004. Introducción a la teratología: el estudio de las malformaciones congénitas en medicina veterinaria. Disponible en: http:// www.monografias.com/trabajos $10 /$ tera/ tera.shtml (01-01-08).

Frazer, C.M. 1991. Congenital an inherited anomalies. In: The Merck veterinary manual. Merck \& CO. Inc. Rahway. N.J. USA. pp. 478.

Homedes, J. y Haro, F. 1967. Suinos. Vigor constitucional y caracteres patológicos letales. En: Zoogenética. Edic. Revolucionaria. La Habana. pp. 369-382.

Johansson, I. y Rendel, J. 1972. Genética y mejora
De acuerdo con Pérez y Suárez (2000), respecto a que la solución de un problema que tiene un origen genético (genes indeseables o alteraciones cromosómicas) es a través de la eliminación de los individuos que portan la alteración y hasta donde sea posible de los animales emparentados con el padre, hermanos e hijos. Este trabajo estuvo encaminado a solucionar algunas de estas afecciones, sobre todo las que resultan compatibles con la vida con el fin de aprovechar su producción de carne, nunca para ser utilizados en la reproducción.

\section{CONCLUSIONES}

Las malformaciones congénitas afectaron al 9,07\% del total de camadas observadas y en orden de importancia fueron: hernia inguinoescrotal, hernia umbilical, atresia anal, contractura del tendón flexor, criptorquidia, atresia anal con fístula rectovaginal, esquistosoma reflejo y microcefalia.

animal. Ed. Acribia. Zaragoza. pp. 249-274.

Pascual del Cueto, C., Pulgarón, P.P. y Castellanos, M. 2000. Herencia de la Salud. En: Genética Animal. Ed. Félix Varela. La Habana. pp. 257323.

Pérez, T. y Suárez, M.A. 2000. Trastornos genéticos de la reproducción. Rev. AC-PA, 1: 31-35.

Pulgarón, P.P. y Pascual del Cueto, C. 1979. Heredopatología en Animales de Explotación. En: Manual de Genética y Mejora Animal. Ed. Pueblo y Educación. La Habana. pp. 208-257.

Reyes, I.R., Antúnes, G., Pérez, F. y Reyes, L.E. 2006. Schistosoma reflexus incompleto en una cerdita mestiza Criolla de Cuba x Yorkshire. Caso clínico. REDVET. VIII (05). (Online). Disponible en: http://www.veterinaria.org (01-0108).

Quiles, A. 2004. Factores que inciden en la mortalidad neonatal en los lechones. VETUY.AgroyVeterinaria (Online). Disponible en: http://www.vet-uy.com/articulos/cerdos/050/ 0023/porc023.htm. (01-01-08).

Archivos de zootecnia vol. 59, núm. 228, p. 604. 